\title{
Modeling the Spatial Effects of the Impact of Innovation on Regional Economic Growth
}

\author{
Vladimir A. Balash*[0000-0002-6987-4799], Olga S. Balash ${ }^{[0000-0003-0405-1836]}$, \\ Alexey R. Faizliev ${ }^{[0000-0001-6442-4361]}$, Elena V. Chistopolskaya ${ }^{[0000-0003-0023-0992]}$ \\ Saratov State University, Saratov, Russian Federation \\ *vladimirbalash@yandex.ru
}

\begin{abstract}
In this paper, we analyze $\sigma$ - and $\beta$-convergence using data from the socioeconomic development of the Russian regions and reveal the role of spatial autocorrelation in regional economic development. We consider 80 regions of Russia for the period 2010-2017. We estimate spatial autocorrelation based on Moran's coefficients. We construct a Moran scatter plot of GDP per capita and the growth rate of GDP per capita in 2017 compared to 2014. We investigate the impact on investment growth in fixed capital and the expenditure on technological innovation. We evaluate a wide range of specifications of spatial econometric models for different weight matrices. It is shown that according to the results of estimation of conditional $\beta$-convergence models, the models of 2010-2014 and 2014-2017 differ significantly. There is a statistically significant $\beta$-convergence for the period 2010-2014, as well as the presence of spatial autocorrelation. However, according to the results of estimation models constructed from data after 2014, the estimates of the coefficients for the explanatory variables are not significantly different from zero and there is no trend toward regional convergence in terms of economic development. All conclusions obtained in the work are resistant to the choice of spatial weights matrices and model specifications.
\end{abstract}

Index Terms - regional disparity, convergence, spatial autocorrelation, spatial econometrics, spatial spillovers

\section{INTRODUCTION}

The problems of disparities in regional economic development have long been discussed by economists. Despite the measures of government agencies aimed at equalizing the economic development of the regions, the problem of uneven economic development of the Russian regions is remains. While in some regions there has been an active increase in production and investment, other regions are facing serious economic and social problems. Therefore, the goal of our research is to study the economic growth and convergence of the regions of Russia. Convergence refers to the process of rapprochement in time of the development levels of countries and regions. Exploring convergence, check the presence of $\sigma$ and $\beta$-convergence. Unconditional (absolute) $\beta$-convergence is a rapprochement of development levels of regions in time. The theory considers convergence between regions subject to the existence of a common stationary state and the convergence of regions to their own stationary states, which implies the absence of convergence of development levels. Conditional $\beta$ convergence implies a mismatch of stationary states, that is, in the long term, differences between regions do not disappear, but remain constant over time.

\section{The Theoretical Model}

When studying convergence, its presence is checked in two forms: $\sigma$ and $\beta$. $\sigma$-convergence implies a reduction in the spread of per capita gross regional product (GDP) and the existence of a tendency to equalize levels of economic development in the long term. The following measures are used to measure sigma convergence unweighted standard deviation, coefficient of variation, Gini Index, Tail index, etc. $\beta$ convergence is based on the Solow model [1], which suggests a decrease in dispersion of GDP per capita or other indicators of income over time:

$$
\frac{y_{i, T}}{y_{i, t}}=\phi_{i}\left(y_{i, t}\right)
$$

where $i$ is the region number, $i=1,2, \ldots, n ;(t, t+1, \ldots, T)$ is the time interval; $y_{i, t}, y_{i, T}$ is GDP per capita in region $i$, respectively, of the base and current year; $\phi_{i}$ is a decreasing function.

The basic econometric model is:

$$
\ln \left(\frac{y_{i, t+k}}{y_{i, t}}\right)=\alpha+\beta \ln \left(y_{i, t}\right)+\epsilon_{i, t},
$$

where $y_{i, t}$ is GDP per capita in region $i$ at time $t ; \alpha, \beta$ are parameters to be estimated; $\epsilon_{i, t}$ is error term.

The convergence rate is calculated:

$$
\hat{b}=-\frac{\ln (1-\hat{\beta} T)}{T},
$$

time to overcome half of the initial GDP per capita inequalities:

$$
h l=\frac{\ln 2}{\hat{b}} .
$$

If there is absolute convergence, then the coefficient estimates for all regions will be the same. If it is not, then they are different and depend on the socio-economic characteristics of the $X_{i}$ regions. That is, the hypothesis of conditional convergence assumes that convergence occurs when the structural characteristics of the economy (for example, demographic situation, government policy, human capital, investment, etc.) affect the growth rate of GDP. In this case, the conditional convergence model has the form:

$$
\ln \left(\frac{y_{i, t+k}}{y_{i, t}}\right)=\alpha_{0}+\beta_{0} \ln \left(y_{i, t}\right)+X_{i}^{\prime} \gamma+\epsilon_{i, t}
$$

where $\gamma$ is the vector of regression coefficients for control variables. 
Convergence models were tested on different types of data: cross-sectional, time series, panel. It was noted that $\beta$-convergence suggests a negative correlation between the average GDP growth per capita over period $k$ and the baseline GDP. However, in some works it was proved that finding a negative convergence parameter does not necessarily mean a decrease in variance in the level of per capita GDP in the cross-sectional data or $\sigma$-convergence. For example, Quah [2] showed that for cross-sectional data there is a negative correlation between growth rates and the initial level, which is achieved with a stable dispersion in income levels. This is due to the presence of growth rate shocks in a particular country, which can compensate for negative $\beta$ coefficients. The problem of convergence of economic growth of territories is widely discussed in the academic literature. There are several concepts that have their own methodology. So R. Barro and $\mathrm{H}$. Sala-i-Martin distinguish $\sigma$-convergence and $\beta$-convergence [3]. $\sigma$-convergence occurs when the dispersion of development indicators (for example, GDP or per capita income) gradually decreases. The presence of $\beta$-convergence is a prerequisite for the existence of $\sigma$-convergence, but not in the opposite direction. $\beta$-convergence means a trend towards a decrease in the differentiation of economic development, while lagging countries or regions have higher rates of economic growth than more developed territories, thus reducing the gap in the level of economic development. The concept of convergence is based on the assumption of the Solow model, which describes the change in capital-labor ratio during the country's movement to a stationary state. A. A. Iodchin describes models for estimation convergence of countries in terms of economic growth and provides econometric equations of relative convergence [4]. The concept of convergence, as well as the basic concepts, methods of its measurement and analysis of the work of Russian scientists, was made in her article by Yu. A. Pshenichnykh [5].

Many scientists have tested hypotheses about the presence or absence of convergence at the national level [6]. Such studies are based on different approaches, from neoclassical to models of endogenous economic growth, as well as empirical studies based on the analysis of statistical data for one period to time series and panel data, including the international level [6]. Most regional studies of income convergence are mainly focused on traditional methods of analysis of $\beta$-convergence, but in the last decade there have been many studies that take into consideration the spatial aspect in models.

Lopez-Rodriguez in his study considers the issues of regional convergence [7]. Fisher and Stirbek [8] model the spatial effects of income convergence per capita in the EU. Researchers Egger and Pfaffermair used per capita GDP data to analyze the effects of spatial interdependence on the Solow model of the European Union countries as well. The results were obtained that the convergence rate depends on the location of the region, highlighted the impact of the remoteness of the region, the actual rate of convergence and the impact of the initial gap in economic development [9]. This allows us to raise the question of the similarity or difference in the rates of convergence in regions closely located relative to each other, and also to take into consideration the territorial aspects of uneven economic development.

Ray, Fernadness, and Maccab estimate the spatial model of inequality in GDP growth per capita in India and China [10], [11]. The problems of convergence and spillover effect of Turkey are research in their work by Kundar and Dogan [12].

Finglengton and Lopez-Bazo analyze the relationship of external factors affecting the economies of neighboring countries using tools of spatial econometrics [13], [14]. Ertur and Koch examine the interdependence of the level of development of technology in neighboring countries. The authors argue that technological interdependence is a spatial external factor and geographical proximity is important for the development of country technologies [15]. Lesage and Fisher in their work conclude that the spatial dependence between the regions and its structure are a variable that determines the long-term regional income level [16].

Koe and Helpman (1995) studied the impact of the level of innovation development of neighboring countries. Studying the influence of R\&D reserves in the country and abroad on the total productivity of factors of production, the paper concluded that the total factor productivity of a country depends not only on the level of development of innovations in a given country, but also on the development of innovations of neighboring countries [17].

An econometric analysis of spatial effects in the convergence models of Russian regions is presented in the works of O.S. Balash [18], [19], N. S. Gichieva [20], O. A. Demidova [21], [22]. Econometric analysis allows us to conclude that for the development of the Volga and Southern Federal District territories, the geographical location of the regions is significant.

E. A. Kolomak analyzed in her work the dynamics of the development of regional budgets, as well as the impact of existing budget policies on the presence or absence of convergence using econometric methods [23].

\section{Methodology}

To detect spatial autocorrelation between regions using the Moran's coefficient (Global Moran's):

$$
I=\frac{n}{S_{0}} \frac{\sum_{i=1}^{n} \sum_{j=1}^{n} w_{i j}\left(y_{i}-\bar{y}\right)\left(y_{j}-\bar{y}\right)}{\sum_{i=1}^{n}\left(y_{i}-\bar{y}\right)^{2}},
$$

where $y_{i}$ is the GDP per capita; $S_{0}=\sum_{i=1}^{n} \sum_{j=1}^{n} w_{i j}$ is the sum of the weights of the matrix $W ; n$ is the number of regions.

The value of the Moran's coefficient depends on spatial weights matrix $W$. As a rule, one of the following options is used: an adjacency matrix (neighborhood), inverse distance spatial matrix, or matrix of squared inverse distances.

The square adjacency matrix consists of elements equal to 1 if the regions are adjacent to each other, and otherwise to zero. The size of the matrix is equal to the number of regions. 
When using the inverse distance matrix, as weights use the distance between the capitals or geographical centers of the regions. It is possible to use distances by rail or road.

Also, for calculations, they often calculate the matrix of squared distances between regions.

The spatial autocorrelation coefficient shows the degree of linear relationship between the vector $Z$ of the centered values of the attribute $\mathrm{X}$ and the vector $W Z$ of the spatially weighted centered values of the attribute $y$ in neighboring regions.

Moran's spatial autocorrelation coefficient varies from -1 to 1: if it is equal to zero, then there is no spatial correlation, if negative, there is a negative spatial correlation, if greater than zero, a positive spatial correlation.

The scatter of the values of the investigated trait relative to the spatial lag is visualized by a spatial scatter plot (Moran Scatter Plot). The abscissa shows the values of the vector $z$ of the standardized feature:

$$
z=\frac{Y-\bar{Y}}{s d(Y)}
$$

the ordinate axis shows the values of the vector $W Z$ of spatially-weighted values of the standardized attribute in neighboring regions. The diagram shows the regression line $W Z$ on $Z$, the slope of which is equal to the coefficient of total spatial autocorrelation $I$.

For objects that fall into the first and third quadrants of the Moran Scatter Plot, there is a positive spatial correlation between the values of the modeled indicator. That is, objects with high or low levels of the observed trait are surrounded by similar ones. In the second (upper left) quadrant are objects with a low level of the simulated indicator, while their neighbors have high. values. The group of objects located in the fourth quadrant is characterized by high values of the trait being studied, while their neighbors are characterized by low values.

Spatial models are based on the premise that the economic development of regions is affected by the degree of economic development of neighboring territories. The influence of neighboring territories is manifested both directly, for example, through innovation, investment flows, the labor market, and implicitly, for example, through interaction at the level of enterprises or public institutions. The use of models with a spatial weights matrix makes it allows to take into account the mutual influence of factors that influence the economic growth of territories. External spatial effects are explained by a similar reaction to external macroeconomic shocks and territorial heterogeneity.

The conditional $\beta$-convergence model with autoregressive spatial lag (SAR) suggests that there is interdependence between the values of the dependent variable in neighboring regions. The mutual influence depends on the elements of the weights matrix $W$ and the value of the spatial autocorrelation coefficient $\rho$ :

$$
\begin{aligned}
\ln \left(\frac{y_{i, t+k}}{y_{i, t}}\right)=\beta_{0}+\rho \sum_{j=1}^{N} w_{i j} & \ln \left(\frac{y_{j, t+k}}{y_{j, t}}\right)+ \\
& +\beta_{1} \ln \left(y_{i, t}\right)+X_{i}^{\prime} \gamma+\epsilon_{i, t},
\end{aligned}
$$

where $\ln \left(\frac{y_{i, t+k}}{y_{i, t}}\right)$ is the logarithm of the GDP growth rate per capita, $N$ is the number of regions, $\rho$ is the spatial autocorrelation coefficient, $\sum_{j=1}^{N} w_{i j} \ln \left(\frac{y_{j, t+k}}{y_{j, t}}\right)-$ is the weighted average of the logarithm of the GDP growth rate in all regions with weights $w_{i j}, X_{i}$ are variables included to control the impact of innovation and investment on the economic growth of the regions.

The spatial error model (SEM) can be written as follows:

$$
\begin{aligned}
\ln \left(\frac{y_{i, t+k}}{y_{i, t}}\right) & =\beta_{0}+\beta_{1} \ln \left(y_{i, t}\right)+X_{i}^{\prime} \gamma+\nu_{i, t}, \\
\nu_{i, t} & =\lambda \sum_{j=1}^{N} w_{i j} \nu_{i, t}+\epsilon_{i, t} .
\end{aligned}
$$

This model assumes that spatial dependence exists in the unexplained part of the change in GDP per capita of the base year. The SAC Model includes both a spatially lagged dependent variable and a spatially auto-correlated error term:

$$
\begin{gathered}
\ln \left(\frac{y_{i, t+k}}{y_{i, t}}\right)= \\
\beta_{0}+\rho \sum_{j=1}^{N} w_{i j} \ln \left(\frac{y_{j, t+k}}{y_{j, t}}\right)+\beta_{1} \ln \left(y_{i, t}\right)+X_{i}^{\prime} \gamma+\epsilon_{i, t}, \\
\nu_{i, t}=\lambda \sum_{j=1}^{N} w_{i j} \nu_{i, t}+\epsilon_{i, t} .
\end{gathered}
$$

The Durbin model (SDM) can be considered if it is assumed that there is no endogenous interaction and that the emphasis is placed on neighborhood externalities:

$$
\begin{aligned}
\ln \left(\frac{y_{i, t+k}}{y_{i, t}}\right)= & \\
=\beta_{0}+\rho \sum_{j=1}^{N} w_{i j} & \ln \left(\frac{y_{j, t+k}}{y_{j, t}}\right)+\beta_{1} \ln \left(y_{i, t}\right)+ \\
& \quad+X_{i}^{\prime} \gamma+\delta \sum_{j=1}^{N} w_{i j} \ln \left(y_{j, t}\right)+\epsilon_{i, t} .
\end{aligned}
$$

Models are estimated using maximum likelihood. One of the major benefits of spatial regression models is their opportunity to quantify spatial spillovers. For this, direct, indirect and cumulative effects are calculated [24]. The direct effect is found as the average change across the regions in the growth rate of GDP per capita in the region when the basic level of GDP per capita in the same region changes. An indirect effect, or an overflow effect, is the average change in the growth rate in a region with a change in the GDP of the base year in all other regions. The overall effect is the sum of the direct and indirect effects. 
Using the values of direct and indirect effects, we can calculate the proportion of direct and indirect effects in the total effect. The proportion of direct effects shows the influence of one's own region on neighboring ones. The greater the value of the share of indirect effects, the greater the impact of this region on what is happening in other regions.

\section{EMPIRICAL ANALYSIS}

The aim of the study is to test conditional $\beta$-convergence models that take into account the spatial interdependence of regional economic growth rates and assess the values of direct and indirect (spillover) effects of investments and innovations.

At present, in Russia there are 89 subjects - republics, regions, autonomous okrugs. However, due to the lack of statistics from 2010 to 2015 for the Republic of Crimea, the city of Sevastopol, as well as the disaggregation of the Tyumen and Arkhangelsk regions since 2012, we analyzed data for 80 regions. That does not affect the results.

We use official data of the Russian statistical data service (Rosstat) for 80 Russian regions from 2010 to 2017. The variables in analysis:

$y$ is GDP per capita in rubles,

Cap is investments in fixed capital in million rubles,

Tech is the expenditure on technological innovation in the regions in million rubles.

Weight matrices were calculated based on data on the geographical boundaries of the regions, and the distances between regional centers (capitals) by road.

\section{A. $\sigma$-Convergence}

The differences in the amount of GDP per capita in the regions of Russia are great. In 2010, almost 20.2 times the GDP per capita of the "rich" regions exceeded the "poor" in 2010 , in 2017 - 16.5 times.

To study $\sigma$-convergence usually analyze the dynamics of different indicators of variation and inequality.

The box plot presented in Fig. 1 shows that differentiation of regions increased in the period under review. Six regions with the highest GDP per capita: Tyumen Region, Sakhalin Region, Chukotka Autonomous Okrug, Moscow, Magadan Region, Republic of Sakha (Yakutia), St. Petersburg. The value of GDP per capita is taken for the Tyumen and Arkhangelsk regions within the boundaries until 2012.

As can be seen from Fig. 1 at current prices, GDP per capita for the period from 2010 to 2017 increased in all regions.

Figure 2 shows the coefficients of variation unweighted and weighted in terms of population. The fact that the values of the weighted coefficient of variation is greater than the unweighted one is due to the fact that regions with high GDP per capita, as a rule, are regions with a larger population. The values of the coefficients of variation fluctuate slightly in time, so there is no reason to talk about the manifestation of the effects of $\sigma$-convergence in the period under consideration.

A similar conclusion is drawn from a study of the dynamics of the values of the Gini coefficient (Fig. 3). The tendency to reduce inequality was manifested in 2010-2013, but since

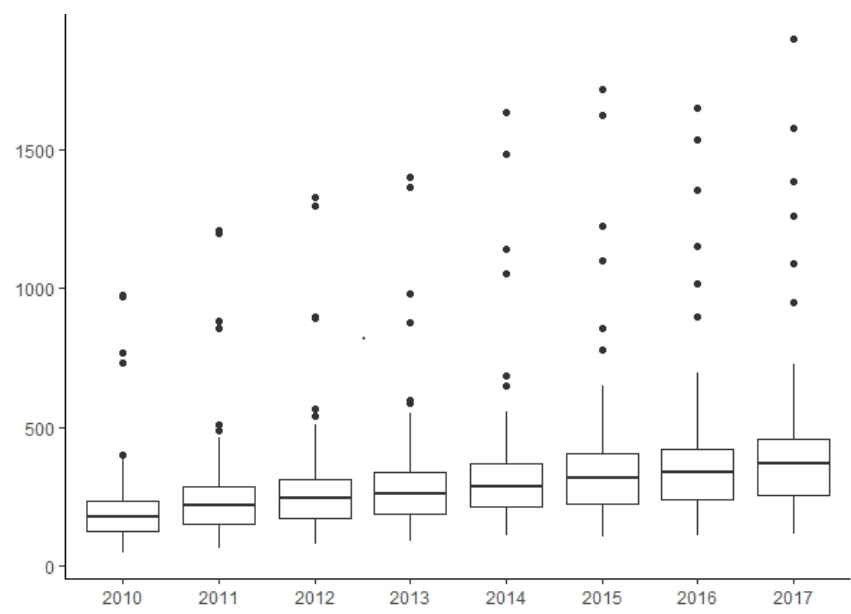

Fig. 1. Dispersion of GDP per capita in the regions of Russia for 2010-2017

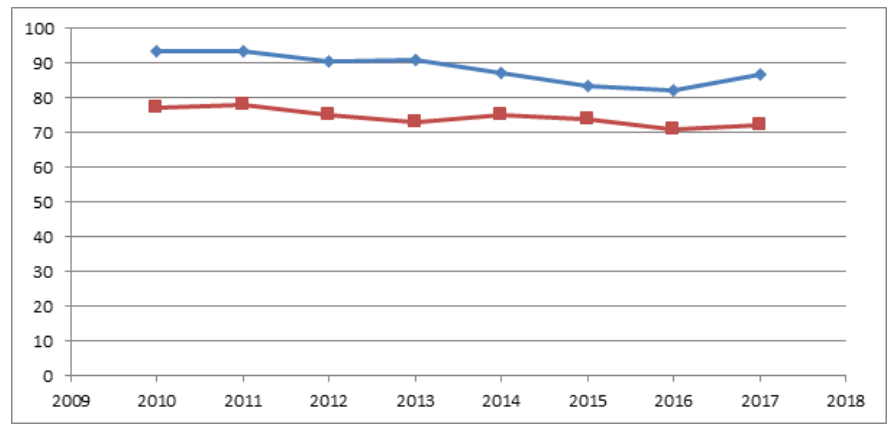

Fig. 2. Dynamics of the coefficient of variation (bottom) and the weighted coefficient of variation of the GDP per capita of Russia in 2010-2017,\%

2014 increased the polarization of regions in terms of GDP per capita.

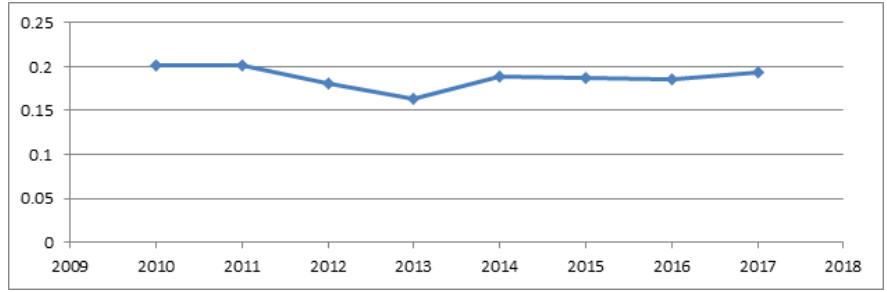

Fig. 3. Dynamics of the Gini coefficient of GDP of Russia for 2010-2017

Let us present the results of estimation the indicators of spatial interdependence of the studied indicators.

Table I presents the values of the Moran's coefficient for the growth rate of GDP per capita. The weights matrix was calculated based on the adjacency matrix of regions (the presence of a border between them). For all the considered periods, there is a significant positive spatial autocorrelation between the growth rates of GDP per capita in the regions of Russia.

Figure 4 shows the Moran Scatter Plot, on which plotted along the $O X$ axis the standardized values of the spatial lag of GDP per capita growth rate of 2017 compared to 2014, and 
the growth rate of GDP per capita and the initial levels of GDP per capita in the regions.

There are two varieties of $\beta$-convergence: absolute (unconditional) and conditional convergence. We study conditional regional convergence, including $\log \left(\mathrm{Cap}_{t+k} / \mathrm{Cap}_{t}\right)$ and the logarithm of the growth rate of expenditure on technological innovation the regions $\log \left(\right.$ Tech $_{t+k} /$ Tech $\left._{t}\right)$ as control variables. Different durations of the periods were chosen by us in order to track the possible difference in the trends of the studied process before and after 2014 .

The results are presented in tables II,III.

shown along the $O Y$ axis the standardized values of GDP per capita growth rate of 2017 compared to 2014, the regression line is the slope coefficient corresponding to the value of the Moran's spatial autoregression coefficient for the GDP per capita growth rate in 2017 compared to 2014 .

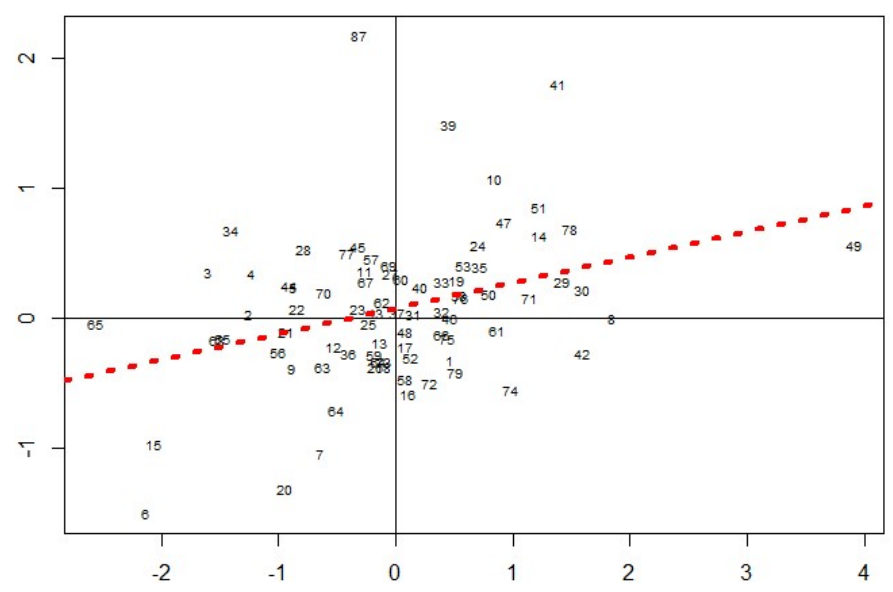

Fig. 4. Moran Scatter Plot of per capita GDP growth rates for 2014-2017

As can be seen from Fig. 4, the Kamchatka Territory (41), Kaliningrad Oblast (39), St. Petersburg (78), Moscow Oblast (51), Republic of Karelia (10), etc. fell into the first quadrant of regions with high GDP per capita growth rates, surrounded by the same neighbors.

The third quadrant includes regions with low per capita GDP growth, surrounded by the same neighbors: the Republic of Ingushetia (6), the Republic of North Ossetia-Alania (15), the Chechen Republic (20), Saratov Region (64), etc.

In the second quadrant (regions with low GDP per capita, surrounded by neighbors with high growth rates): Chukotka Autonomous Okrug (87), Volgograd Oblast (34) and others, in the fourth quadrant of regions with low GDP per capita, surrounded by neighbors with high growth rates, Kemerovo (42), Chelyabinsk (74) regions, Jewish Autonomous Region (49) and others.

\section{B. $\beta$-Convergence}

$\sigma$-convergence captures regional differences in the variance of regional GDP per capita. However, this is not enough for convergence analysis. The $\beta$-convergence model suggests faster growth in lagging regions. If the $\beta$-convergence hypothesis is true, we expect to see a negative correlation between
TABLE II

CONDITIONAL $\beta$-CONVERGENCE MODELS FOR 2010-2014. THE WEIGHT MATRIX IS ADJACENCY MATRIX

\begin{tabular}{|c|c|c|c|c|}
\hline & SLM & SEM & SDM & SAC \\
\hline Constant & $\begin{array}{c}0.980 * * * \\
(0.248)\end{array}$ & $\begin{array}{c}1.149 * * * \\
(0.219)\end{array}$ & $\begin{array}{c}0.907 * * * \\
(0.417)\end{array}$ & $\begin{array}{c}0.671 \\
(0.695)\end{array}$ \\
\hline $\log \left(y_{i, t}\right)$ & $\begin{array}{c}-0.055 * * * \\
(0.018)\end{array}$ & $\begin{array}{c}-0.062 * * * \\
(0.018)\end{array}$ & $\begin{array}{c}-0.047 * * * \\
(0.022)\end{array}$ & $\begin{array}{c}-0.047 * * * \\
(0.022)\end{array}$ \\
\hline $\log \left(\frac{C a p_{i, t+k}}{C a p_{i, t}}\right)$ & $\begin{array}{c}0.112 * * * \\
(0.030)\end{array}$ & $\begin{array}{c}0.119 * * * \\
(0.030)\end{array}$ & $\begin{array}{c}0.107 * * * \\
(0.030)\end{array}$ & $\begin{array}{c}0.109 * * * \\
(0.031)\end{array}$ \\
\hline $\log \left(\frac{\text { Tech }_{i, t+k}}{\text { Tech }_{i, t}}\right)$ & $\begin{array}{c}0.025 * * * \\
(0.007)\end{array}$ & $\begin{array}{c}0.027 * * * \\
(0.007)\end{array}$ & $\begin{array}{c}0.023 * * * \\
(0.008)\end{array}$ & $\begin{array}{c}0.021 * * * \\
(0.008)\end{array}$ \\
\hline $\begin{array}{l}\text { The spatial lag } \\
\log \left(y_{i t}\right)\end{array}$ & & & $\begin{array}{l}0.0002 \\
(0.037)\end{array}$ & $\begin{array}{c}0.014 \\
(0.047)\end{array}$ \\
\hline $\begin{array}{l}\text { The spatial lag } \\
\log \left(\frac{C a p_{i, t+k}}{C a p_{i, t}}\right)\end{array}$ & & & $\begin{array}{l}-0.0005 \\
(0.052)\end{array}$ & $\begin{array}{l}-0.030 \\
(0.080)\end{array}$ \\
\hline 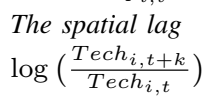 & & & $\begin{array}{c}0.025^{* * *} \\
(0.013)\end{array}$ & $\begin{array}{c}0.021 \\
(0.019)\end{array}$ \\
\hline$\rho$ & $0.180^{*}$ & & 0.088 & 0.278 \\
\hline$\lambda$ & & $0.073 *$ & & -0.228 \\
\hline Log likelihood & 86.28 & 85.49 & 88.31 & 88.41 \\
\hline Observations & 80 & 80 & 80 & 80 \\
\hline AIC & -160.57 & -158.98 & -158.63 & -156.81 \\
\hline
\end{tabular}

The results of the estimation of models according to 2010 2014 and 2014-2017 differ significantly. In the first subperiod, the coefficients of the explanatory variables are significantly different from zero. The sign of the coefficient in the logarithm of GDP in the base period is negative, which corresponds to the assumption of the presence of $\beta$-convergence. In addition, the growth rate of investment in fixed assets and the expenditure on technological innovation had a significant impact on economic growth. The significance and positive value of the spatial lag in the rate of growth of expenditure on technological innovations confirms the hypothesis that there is a dependence of the average GDP growth per capita on the rate of growth of expenditure on technological innovations in neighboring regions. These conclusions are resistant to the specification of the model and the choice of spatial weights matrices. Note that the hypothesis of the substantial presence of spatial autocorrelation (non-zero coefficient $\rho$ ) is confirmed for the SEM and SLM models, but not for the SDM. But in the SDM model, spatial interdependence is taken into account by 
TABLE III

CONDITIONAL $\beta$-CONVERGENCE MODELS FOR 2014-2017. The Weight Matrix Is AdJACEnCy MatriX

\begin{tabular}{|c|c|c|c|c|}
\hline & SLM & SEM & SDM & SAC \\
\hline Constant & $\begin{array}{l}-0.005 \\
(0.246)\end{array}$ & $\begin{array}{c}0.034 \\
(0.261)\end{array}$ & $\begin{array}{c}0.254 \\
(0.462)\end{array}$ & $\begin{array}{l}-0.258 \\
(0.540)\end{array}$ \\
\hline $\log \left(y_{i, t}\right)$ & $\begin{array}{c}0.013 \\
(0.020)\end{array}$ & $\begin{array}{c}0.014 \\
(0.021)\end{array}$ & $\begin{array}{l}-0.002 \\
(0.022)\end{array}$ & $\begin{array}{l}-0.002 \\
(0.024)\end{array}$ \\
\hline $\log \left(\frac{C a p_{i, t+k}}{C a p_{i, t}}\right)$ & $\begin{array}{c}0.014 \\
(0.032)\end{array}$ & $\begin{array}{c}0.011 \\
(0.033)\end{array}$ & $\begin{array}{c}0.003 \\
(0.032)\end{array}$ & $\begin{array}{c}0.004 \\
(0.035)\end{array}$ \\
\hline $\log \left(\frac{\operatorname{Tech}_{i, t+k}}{\text { Tech }_{i, t}}\right)$ & $\begin{array}{c}0.015 \\
(0.009)\end{array}$ & $\begin{array}{c}0.014 \\
(0.009)\end{array}$ & $\begin{array}{c}0.011 \\
(0.009)\end{array}$ & $\begin{array}{c}0.011 \\
(0.010)\end{array}$ \\
\hline $\begin{array}{l}\text { The spatial lag } \\
\log \left(y_{i}\right)\end{array}$ & & & $\begin{array}{c}0.037 \\
(0.040)\end{array}$ & $\begin{array}{c}0.037 \\
(0.049)\end{array}$ \\
\hline $\begin{array}{l}\text { The spatial lag } \\
\log \left(\frac{\operatorname{Cap}_{i, t+k}}{\operatorname{Cap}_{i, t}}\right)\end{array}$ & & & $\begin{array}{c}0.051 \\
(0.051)\end{array}$ & $\begin{array}{c}0.051 \\
(0.057)\end{array}$ \\
\hline $\begin{array}{l}\text { The spatial lag } \\
\log \left(\frac{\text { Tech }_{i, t+k}}{\text { Tech }_{i, t}}\right)\end{array}$ & & & $\begin{array}{c}0.015 \\
(0.016)\end{array}$ & $\begin{array}{c}0.016 \\
(0.022)\end{array}$ \\
\hline$\rho$ & 0.252 & & 0.137 & 0.106 \\
\hline$\lambda$ & & 0.219 & & 0.037 \\
\hline Log likelihood & 87.01 & 86.42 & 89.11 & 89.12 \\
\hline Observations & 80 & 80 & 80 & 80 \\
\hline AIC & -162.01 & -160.84 & -160.22 & -158.23 \\
\hline
\end{tabular}

including regressors in the spatial lag model. Our results are consistent with the findings of previous studies on the presence of $\beta$-convergence of Russian regions in the period 1990-2010 [18], [19].

However, the estimates of the coefficients of the explanatory variables obtained from the results of evaluating models constructed from data after 2014 are not significant nonzero. It is not possible to confirm the conclusions about the preservation of the trend towards the rapprochement of regions in terms of the level of economic development; rather, we can talk about its deceleration or reversal of the trend.

Table IV shows the indirect, direct, and cumulative effects of the Durbin model for the adjacency weights matrix.

TABLE IV

DIRECT, INDIRECT AND CUMULATIVE EFFECTS FOR DURBIN MODELS

\begin{tabular}{|c|c|c|c|}
\hline \multirow[b]{2}{*}{ Variable } & \multicolumn{3}{|c|}{ Adjacency Weight Matrix } \\
\hline & Direct effect & Indirect effect & Aggregate effect \\
\hline $\log \left(y_{i, t}\right)$ & -0.047 & -0.004 & -0.051 \\
\hline $\log \left(\frac{C a p_{i, t+k}}{C a p_{i, t}}\right)$ & 0.107 & 0.010 & 0.117 \\
\hline $\log \left(\frac{\operatorname{Tech}_{i, t+k}}{\text { Tech }_{i, t}}\right)$ & 0.023 & 0.029 & 0.053 \\
\hline
\end{tabular}

If we compare the direct and indirect effects calculated for the adjacency matrix, then the direct effects turn out to be much more indirect. This means that the influence of the logarithm of the base 2010 GDP per capita and the logarithms of the growth rate of investment in fixed capital on the change in the growth rate of GDP per capita is much greater in the own region than in the neighboring ones. The expenditure on technological innovation, on the contrary, have a greater impact on neighboring regions than on their own. The amount of investments in fixed capital of our own region by $92 \%$ affects economic growth, while the expenditure on technological innovation by $44 \%$ are associated with the influence of our own region and $56 \%$ - with neighboring territories.

The use of different weights matrices makes it possible to estimate the robustness of the results for the choice of weights. For all three options for the selection of weights matrices, the results are quite similar and do not affect the conclusions for the periods from 2010 to 2014 , and from 2014 to 2017 .

\section{CONCLUSION}

We applied spatial econometric models to test hypotheses about conditional $\beta$-convergence of Russian regions of GDP per capita. As control variables were used the growth rate of investment in fixed capital and the expenditure on technological innovation. For modeling spatial effects were compared the results for different options for constructing weights matrices: according to the data on the geographical boundaries of regions and the distances between regional centers (capitals) by road.

Based on the results of estimation conditional $\beta$ convergence models according to data from 2010 to 2017 , we found that the models of 2010-2014 and 2014-2017 are significantly different. For the period 2010-2014, there is a statistically significant $\beta$-convergence, as well as the impact on the growth rate of investment in fixed capital and the expenditure on technological innovation. We also found that the average GDP per capita growth rate is dependent on the growth rate of expenditure on technological innovation in neighboring regions and the effects of their influence. Our findings are resistant to weights matrix selection and model specifications.

However, according to the results of estimation models constructed from data after 2014, the estimates of the coefficients for the explanatory variables are not significant, they differ from zero. In this period, there is no trend towards regional rapprochement in terms of economic development.

\section{ACKNOWLEDGMENTS}

The reported study was funded by the Russian Science Foundation according to the research project 19-18-00199.

\section{REFERENCES}

[1] R. Solow, "A contribution to the theory of economic growth," The Quarterly Journal of Economics, vol. 70, no. 1, pp. 65-94, 1956. [Online]. Available: https://EconPapers.repec.org/RePEc:oup:qjecon:v: 70:y:1956:i:1:p:65-94.

[2] D. Quah, "Empirical cross-section dynamics in economic growth," European Economic Review, vol. 37, no. 2-3, pp. 426-434, 1993. [Online]. Available: https://EconPapers.repec.org/RePEc:eee:eecrev:v: 37:y:1993:i:2-3:p:426-434

[3] R. Barro and X. Sala-i Martin, "Convergence across states and regions," Brookings Papers on Economic Activity, vol. 22, no. 1, pp. 107182, 1991. [Online]. Available: https://EconPapers.repec.org/RePEc:bin: bpeajo:v:22:y:1991:i:1991-1:p:107-182 
[15] C. Ertur and W. Koch, "Growth, technological interdependence and spatial externalities: theory and evidence," Journal of Applied Econometrics, vol. 22, no. 6, pp. 1033-1062, 2007. [Online]. Available: https://EconPapers.repec.org/RePEc:jae:japmet:v:22:y:2007: i:6:p:1033-1062

[4] A. Iodchin, "Decomposition of regional convergence in Russia," Audit and financial analysis, no. 4, pp. 475-482, 2007.

[5] J. Pshenichnykh, "Methodological foundations of convergence research," Bulletin of the Taganrog Institute of Management and Economics, vol. 2, 2015.

[6] W. J. Baumol, "Productivity growth, convergence, and welfare: What the long-run data show," The American Economic Review, vol. 76, no. 5, pp. 1072-1085, 1986. [Online]. Available: http: //www.jstor.org/stable/1816469

[7] J. Lopez-Rodriguez, "Regional convergence in the european union: Results from a panel data model," Economics Bulletin, vol. 18, pp. 1-7, 052008.

[8] M. M. Fischer and C. Stirböck, "Regional income convergence in the enlarged Europe, 1995-2000: A spatial econometric perspective," ZEW - Centre for European Economic Research Discussion, pp. 1-28, 2004.

[9] P. Egger and M. Pfaffermayr, "Spatial convergence," Papers in Regional Science, vol. 85, no. 2, pp. 199-215, 2006. [Online]. Available: https://rsaiconnect.onlinelibrary.wiley.com/doi/abs/10.1111/j. 1435-5957.2006.00084.x

[10] R. Rohan and F. Cledwyn, "India and China's growth spillover in Asia: A spatial panel econometric approach," in 14th Annual Conference on Economic Growth and Development, 2018, pp. 1-28.

[11] A. Mccabe, "Economy on pace to become world," Gazette Montreal, no. 2, pp. 1-2, 2010.

[12] A. Kýndap and T. Dogan, "Regional economic convergence and spatial spillovers in Turkey," International Econometric Review (IER), vol. 11, no. 1, pp. 1-23, 2019. [Online]. Available: https://EconPapers.repec.org/RePEc:erh:journl:v:11:y:2019:i:1:p:1-23

[13] B. Fingleton and E. López-Bazo, "Empirical growth models with spatial effects*," Papers in Regional Science, vol. 85, no. 2, pp. 177198, 2006. [Online]. Available: https://EconPapers.repec.org/RePEc:bla: presci:v:85:y:2006:i:2:p:177-198

[14] E. López-Bazo, E. Vayá, and M. Artís, "Regional externalities and growth: Evidence from European regions," Journal of Regional Science, vol. 44, no. 1, pp. 43-73, 2004. [Online]. Available: https://EconPapers.repec.org/RePEc:bla:jregsc:v:44:y:2004:i:1:p:43-73
16] J. P. Lesage and M. M. Fischer, "Spatial growth regressions: Model specification, estimation and interpretation," Spatial Economic Analysis, vol. 3, no. 3, pp. 275-304, 2008. [Online]. Available: https://doi.org/10.1080/17421770802353758

[17] D. T. Coe and E. Helpman, "International r and d spillovers," European Economic Review, vol. 39, no. 5, pp. 859-887, 1995. [Online]. Available: http://www.sciencedirect.com/science/article/pii/001429219400100E

[18] O. Balash, "Convergence spatial analysis of Russia's regions," Izvestiya of Saratov University. New Series. Series: Economics. Management. Law, vol. 12, no. 4, pp. 45-52, 2012.

[19] O. Balash and E. Chistopolskaya, "The spatial approach to the analysis of economic growth in the regions of Russia," in Proceeding of International scientific and economics Conference named after academicial P.P. Maslov, 2013, pp. 12-20.

[20] N. Gichiev, "Regional convergence of economic growth: spatial econometrics," Regional Economics: theory and practice, vol. 16, no. 1, pp. 58-67, 2018.

[21] O. Demidova, "Spatial effects for the eastern and western regions of Russia: a comparative analysis," International Journal of Economic Policy in Emerging Economies, vol. 8, no. 2, pp. 153-168, 2015. [Online]. Available: https://ideas.repec.org/a/ids/ijepee/v8y2015i2p153-168.html

[22] O. Demidova, P. Daddi, E. Medvedeva, and M. Signorelli, "Modeling the Employment Rate in Russia: a Spatial-Econometric Approach," Economy of region, vol. 1, no. 4, pp. 1383-1398, 2018. [Online]. Available: https://ideas.repec.org/a/ura/ecregj/v1y2018i4p1383-1398.html

[23] E. Kolomak, "Models of regional policy: convergence or divergence," Regional Economics: theory and practice, vol. 9, no. 1, pp. 113-120, 2009.

[24] J. P. LeSage and R. K. Pace, Interpreting Spatial Econometric Models. Berlin, Heidelberg: Springer Berlin Heidelberg, 2019, pp. 1-18. [Online]. Available: https://doi.org/10.1007/978-3-642-36203-3_91-1 